\title{
TouchIn: An NFC Supported Attendance System in a University Environment
}

\author{
Media Anugerah Ayu, Member, IACSIT and Barroon Ismaeel Ahmad
}

\begin{abstract}
Registering for attendance in education environments especially universities is a highly demanding activity as a result of increasing number of students. The attendance process normally involves circulating a paper for the students to register their names, or the lecturer calling the names and registering the students either in a paper or from PDA/PC. In the first case the students' attention may be attracted while taking the lectures and at the same time they can register for students who do not being present in the class. While in the latter case the issue of cheating in the form of registering for their friends can be solved but imaging the number of students to be from 50 and above, a great portion of the lecture time will be wasted performing this process. In this paper we propose a smart attendance system using NFC that will simplify the attendance process, by simply touching an attendance poster or the lecturer's NFC based mobile device in the class.
\end{abstract}

Index Terms-NFC technology, NFC mobile application smart attendance system, touching based system, wireless attendance system.

\section{INTRODUCTION}

The issue of attendance registration in present-day institutions is really posing a great challenge in academic setting, because of the way the process is done and various hurdles surrounding it. The attendance is an important part of students' academic record; since in some institutions without a certain percentage student cannot sit for an examination, while in some other institutions it is part of the continuous assessment. However, the traditional way of attendance registration is time consuming and prone to cheat by some students. The process involves the lecturer passing a paper to the students in a class to write their names and sign, or find their names in the paper to sign along their names. In this situation some students may deceive the lecturer by signing attendance for their friends who are not present in the class. Another way which is more difficult and time consuming is the lecturer will be calling names from the list of the students that are enrolled into the course, and mark present for each and every student who is in the class. Imagine how many minutes it will take to register attendance in a class of like 100 students in this fashion. These are some of the challenges that call for an improvement in the attendance registration

Manuscript received September 4, 2013; revised December 18, 2013

M. A. Ayu is was with International Islamic University Malaysia, Kuala Lumpur 53100. She is now with Universitas Siswa Bangsa Internasional (USBI), Pancoran, Jakarta 12780, Indonesia (e-mail: media@ieee.org, media@sampoernaeducation.ac.id).

B. I. Ahmad is with Faculty of Information and Communication Technology, International Islamic Universtiy Malaysia, Kuala Lumpur 53100, Malaysia (e-mail: barroonia@gmail.com ). process. Several technologies like Biometric, RFID, NFC, etc can be used to simplify and improve the attendance system, since user identification is the most important aspect that needs to be handled cautiously in this type of applications. In this work we propose a web based attendance system using Near Field Communication (NFC) technology. The NFC technology is now integrated into mobile devices which can be used for online payment, access control, user identification, transfer of personal and private information, etc.

NFC is a new, short range, high frequency, low bandwidth, and wireless communication technology. NFC communication is activated by touching two NFC enabled devices together, or bringing them into close range. The range is usually few centimeters, and it operates at the frequency of $13.56 \mathrm{MHz}$. The maximum data transfer rate is 424kbit/s. NFC is based on Radio frequency Identification (RFID) thus its communication involves initiator and a target, the initiator actively generates a Radio Frequency (RF) field that can be used as a signal to power a passive target. The initiator (active) has its own internal power that can be used to power the ICs that generate the outgoing signal; while the target (passive) has only ICs with no internal power, which makes it to be in different forms like tags, stickers or cards [1].

NFC support three modes of operation they are: reader/writer mode, card emulation mode, and peer to peer mode. The communication in reader/writer mode is between NFC device and a tag in which device either read from a tag or write to a tag. Peer-to-Peer mode involves exchange of data between two NFC devices. While in card emulation mode the NFC device acts as a tag which will appear to an NFC reader as a contact-less smart card. One popular application of NFC is Smart Poster. The concept of Smart Poster is to keep information like URL, phone number, SMS into a tag and attached the tag to a physical object. This information can be accessed by touching the tag with NFC enabled device. The Smart Poster has some actions that can initiate a phone call, can launch a URL, or can send an SMS [2]. In our proposed system two modes of operation will be used: Reader/writer mode (like smart poster) and Peer-to-Peer mode (like android beam).

This paper presents our works in developing an NFC supported attendance system. The presentation in this paper is organized as follows: Section II presents a review on works done by some researches related to attendance management system, which include computer-based attendance systems, and mobile-based attendance systems using various technologies like biometric, RFID and NFC. Section III discussed about the proposed system with its components. The working of the system is explained in Section IV. Finally, 
the last part presents the conclusion and future improvement.

\section{RELATED WORK}

In an effort to improve attendance registration system, researchers worked on the improvement from different perspective. Some systems are computer-based which may be online or offline system. For instance, a desktop application developed by Jain et al. [3] in which all the list of registered students for a particular course will be displayed when the lecturer start the application. The attendance registration is done by clicking a check box next to the name of students that are present, and then a register button is clicked to mark their presence. Another similar project was proposed, but in this case the student will have to register individually using client server socket program from their device (laptop) [4]. Registering the attendance by proxy is eliminated in the first project since the lecturer will see each and every student in the class, while in the latter case student snapshot is taking by the client application. Even though in both projects the time wastage is also there, but still it is an improvement on the manual process since attendance data can be stored safely and reports can be easily generated. However, Zhang et al. [5] are with the opinion that attendance management is ignored by current educational administration management system, focusing only on register management, education plan, course management, etc. as a result they developed attendance management system using VisualStudio.NET and Oracle. Their system is a web based that used card technology for student's identification, and registering attendance into the database.

Mohamed et al. [6] designed a fingerprint device that is used in fingerprint attendance system. The students mark their presence by placing their finger on the device's sensor. The system components are:

- Handheld device which was constructed and controlled by microcontroller (PIC18F4550) with components (fingerprint module, Real Time Clock RTC, buttons, Graphic Liquid Crystal Display GLCD, Memory, etc).

- Host computer with GUI application for managing the attendance, the application is used to transfer the students' data to the device. The attendance details can be accessed through USB interface and finally store in to the database. [6]

On the other hand, BIS [7] presents a commercial system based on RFID for attendance management for schools and colleges. The system can send SMS and email alert to parents/guardians of the students automatically. The student will register at the gate by touching RFID device with their RFID tag and send the data to BISAM server in the school. The server will process the attendance data and send an SMS to the parents/guardians of the absentee student through BISAM SMS gateway server. The system also has Time Manager Software for managing employees' attendance and HR related functionalities. In [8], [9] RFID reader was designed with microcontroller, transceiver chip, serial communication IC, LCD, USB interface, power supply module, etc as components. When a staff member touches the reader with their card the data is sent to PC manager application which will validate the data and extract information like staff ID and access time into the database [8]. While in [9], when a student touch the reader it sends the data to the microcontroller for comparison with the ID stored in the microcontroller's memory; if ID exist the name, ID and attendance will be displayed on the LCD then transfer the data to PC via RS323 port [9]. Also [10] proposed another system based on RFID where the RFID terminal read the student ID, date and time; and store it into a database in an online server.

The NFC-based applications simplify various human day-to-day activities by simply touching an object fixed or integrated with NFC tag. For instance, SmartTouch is one of the early NFC projects that focuses on NFC technology which was coordinated by VTT Technical Research Centre Finland; applications in various areas were developed under this project such as mobile payment and ticketing, smart poster, attendance system for schools, home use, household access control and security, blood glucose meter, etc. [11]. NFC-enabled services were piloted in schools in Oulu. Some of the services include VIKSU Info Channel that provides homework assignment, meeting, and timetable functionalities. Another project is attendance supervision for secondary and primary school. This service will allow lecturers, administrators and parents to instantly know the attendance status of their children. Laanila upper secondary school students were used for pilot test whereby they will touch a tag on the teacher's desk with their NFC-enabled phone to register their attendance. They receive a response immediately on their phone. The system by default mark the student absent if they did not log in by touching the tag. The system initially calculate lateness after 3 minutes of the starting time, but later changed to 3 minutes after first student register since the teachers can themselves sometimes be late due to other responsibilities. The primary school attendance is aim at providing parents real-time information about their children's arrival and departure. Children at Hintta Primary School were given NFC card holding their information that will be used to touch a reader that will register their arrival or departure and their parents can check it online or choose to receive the information as an SMS. The card can also be used to touch the teacher's phone in order to control the attendance for afternoon care centre. [12]. Data was collected from the users in order to find their experience when using the system; also the analysis revealed that the system will benefit mainly parents and teachers [13].

European Higher Education Area (EHEA) is working on promoting the modernization of the universities throughout Europe, the Technical University of Cartagena worked on developing and implementing Smart University model for realization of intelligent environment. This project has two goals: creating a ubiquitous computing system where relation between people, practice, and technology happen as a part of a natural interaction paradigm, and to deliver applications that replace some of the tasks that cause the teachers, students, and other staff to spend time daily. Two projects were developed they are attendance registering system and administrative payment system (like matriculation charges, transcript of record, certified document charges etc) which are all based on NFC. The hardware used in the project includes NFC-based active devices (Nokia 6212 and 
Samsung Nexus S), NFC-enabled passive devices (Topaz, Touchatag, and Nokia), NFC readers (ACS-ACR-122U), and NFC Server Hosts linked to the university network which handle the communication with the readers. This host runs the software applications that provide access to the reader. In the attendance system each room has NFC reader which is connected to teacher's PC which is connected to the university's network. The students and teachers must download and install the mobile application on their phones that will be automatically run upon touching on the reader. The teacher will activate the lecture group. When the students and teachers application started they will fill a form and transfer the data to the server through the reader, and receive a response also via the reader [14].

Contactless technology especially NFC can be utilized to make university life easier. Therefore, Budapest University of Technology and Economics (BME) introduced NFC-based student attendance monitoring system [15], [16]. The system can be used to track attendance percentage, in order to put the university's rule concerning writing exam without a certain attendance percentage into practice. Biometric identification is added to NFC to avoid impersonation. The students register their attendance from a terminal that has NFC and fingerprint reader using only card that stores student ID and fingerprint. The terminals store the attendance data and it periodically send the data during the day to a back-office system. The terminals as well as back-office store timetable and identification policy. The back-office generates the report from the data received from the terminals. The terminal is capable of storing attendance data for a complete semester [16]. Similarly, a mobile phone attendance system for small office employees was presented [17]. The employee will touch the NFC-enabled mobile device with their card, and then the employee data (ID, Photo, Time in/Time out, and Date) will be sent to the backend system.

Ninomiya et al. [18] proposed a design of NFC and Social Network Service (SNS) based Event management attendance system. In their system the meeting participant when registering for the event will provide their SNS ID (twitter). The goal of the system is to bridge the gap between SNS ID and user using NFC and SNS, since in some situations the participants may be friends in a particular SNS without knowing it while they are in the event. The organizers prepares NFC tags with meeting and session names on the tag, and the participants are assumed to have smart phones or tablets with NFC capability. Although the participants register their SNS ID in the pre-meeting registration website, when they attend they will download application software in their NFC enabled device. The meeting name, session name, and SNS ID must be set by the participant in the application. When the participants touch the tag in the session a message will be send to a server notifying it that the user is in the meeting. The NFC device of the user will receive the SNS ID of the participants who are in the meeting and those that are supposed to attend. With this information the organizers will have the list of those attended the meeting [18].

From the works above it appears that some of the systems developed require the use of computer for attendance registration, while others involve the use of fingerprint, RFID or NFC readers. Therefore, we are proposing an easy to use web based attendance registration system that will require no device other than NFC-enabled device like mobile-phone.

\section{TOUCHIN SYSTEM}

The difficulties and challenges involved in the current attendance registration process in a university environment can be reduced if not completely eliminated by automating the process. Moreover, automating an attendance system will also reduce the time spent unnecessarily on handling this important process in an education institution, especially by looking at how the number of students are keep increasing in our institutions these days. The system proposed in this paper is a web based attendance system utilising NFC technology. We call our proposed system as TouchIn System.

The system has two main units as shown in Fig. 1. The units are reader unit and web server unit. Each of these units has hardware and software components. Essentially, the hardware components for the reader units are NFC-enabled mobile devices and tags, while for the web server unit is a computer that can host web services. Whereas, the software required in the reader unit is the client application that will be installed on NFC-enabled devices. The software requirement for the web server unit is the web based attendance application.

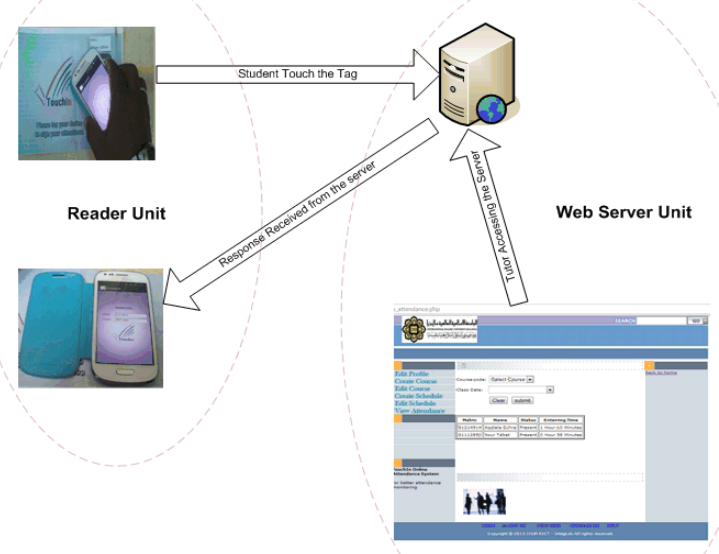

Fig. 1. TouchIn system overview.

\section{A. Reader Unit}

Reader unit is the unit that is responsible for reading the student information like student ID from either student's NFC-enabled mobile device or a tag. If the student is using NFC-enabled mobile device then the student ID is retrieved from a file stored in the device. But if the student is using an NFC tag in the form of card or wristband then the student ID will be retrieved from the tag. Furthermore, for NFC-enabled mobile device user; device ID is used as a way of verifying the student. This ID is read from the device and passes together with the student ID into the server. Apart from student ID, course code is another important field that is needed for the attendance registration. The course code and the address (URL) of the web based application are stored in 
an NFC tag before starting any class. The type of tag used in this work is NFC forum type 2 (MIFARE) tag with 716 bytes size. In developing this system issue of not having NFC-enabled device by some students and or unstable Internet service were taking into consideration; this is because both NFC-enabled device and Internet are mandatory requirements for the system. Consequently three different scenarios will be discussed related to the two issues.

From the three scenarios discussed in the next subsections, we can clearly see that the best option is the first case, where the student has an NFC enabled device and Internet connection. The rationale is that the students can be verified with their device ID, and they can get a response immediately on whether their attendance registration is successful or not. Another advantage is, we can have more than one smart poster for a larger class to reduce the waiting time for the registration. In the second case, we can still verify the students with their device ID but they cannot get a response. Also, for larger classes there will be delay in the process since every student will use the lecturer's mobile device. The last scenario is the least secured especially if student is using a tag since only the student ID is kept in the tag, but it will be a bit more secured if using NFC tag integrated into student ID. However, this has same limitation as in the second scenario.

\section{B. The Students Have NFC-Enabled Device and Internet}

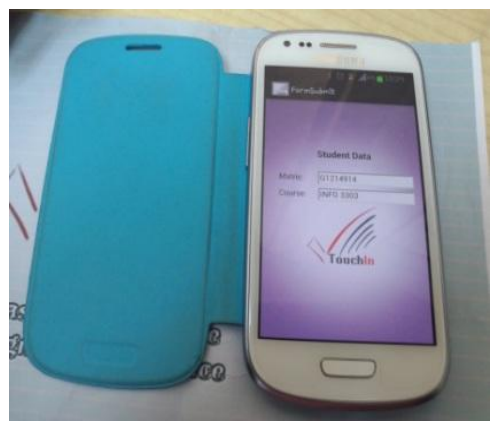

Fig. 2. Poster touched by student's phone.

In this case a tag will be attached to a paper carrying the course detail similar to Smart Poster; the tag will store the URL for the attendance system and the course code. Also the student will have to download and install two applications on their devices. The first application requires the students to enter their student ID and click a button for registration. When this form is sent the student's device ID will be registered in the server and at the same time create a file in the device with the student ID. The second application is the one that will be automatically started when the tag is touched as depicted in Fig. 2. This application will read the student ID from the file created, the device ID, and also the content of the tag. The URL from the tag will be launched and the students ID, course code, device ID will be loaded into a form and automatically submit the form for further processing.

\section{The Students Have NFC-Enabled Device but no Internet}

In this scenario the lecturer must also have NFC-enabled device, and both the devices must support beam functionality. Here the lecturer and student will install two applications. The lecturer before starting any class will run the first application that will set the course code, after which the device will be kept by the side in an active mode. The first application that the student will install will register the device ID and create a file with student ID in their device as in the previous case. Then, when the students want to register for attendance they will run the other application that will fetch the student ID from the file, read the device ID and beam (send) it to the lecturer's device by simply touching the device. Subsequently, the application in the lecturer's device will retrieve the course code and add it to receive student information. The same application will launch the URL of the attendance system and submit all the details into the server.

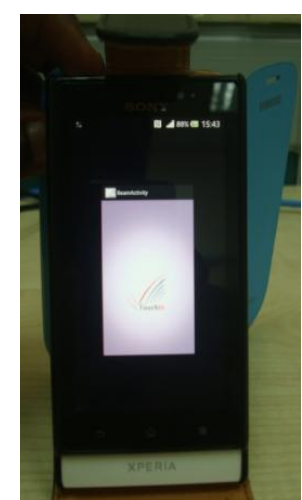

a)

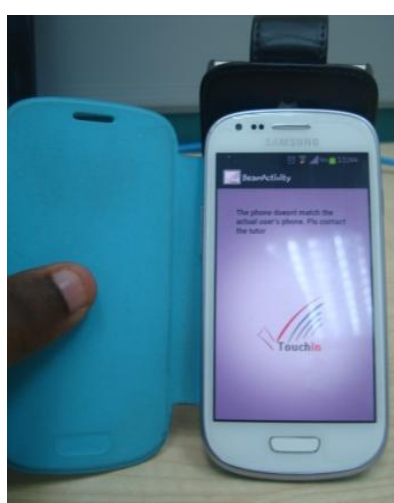

b)
Fig. 3. Beaming data between student's and lecturer's NFC-enabled phones.

Fig. 3 a) shows the student mobile device after the application is started, waiting for the student to touch the screen in order to beam (send) the data. While Fig. 3 b) shows the response after sending the data to the server.

\section{The Students do not Have Both NFC Enabled Devise and Internet}

In this situation, the students are assumed not to have NFC-enabled device. To enable them to use the TouchIn attendance system an NFC tag will be issued to the students to carry their student ID. Or, as another option an NFC tag will be embedded into their student card. In this kind of situation, the lecturer must have NFC-enabled device that each time the students want to register for the attendance they will touch the lecturer's device. Fig. 4 show the communication between the student tag and lecturer's mobile device.

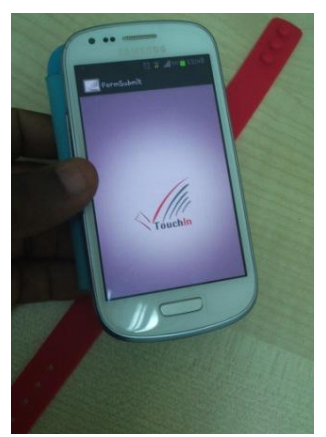

Fig. 4. Touching lecturer's phone by student NFC tag.

\section{E. Web Server Unit}

The Web Server unit is the processing engine for our TouchIn attendance system, since this is where all the operations concerning attendance registration is done. The only hardware required in this unit is a computer that should 
always be online, and has the facilities needed for hosting web services. In other word, a computer that can host our web based attendance application.

The application receives a request from either student or lecturer, and reply with a response depending on the request. A typical request is like attendance registration by a student. The application is designed basically using a server side scripting technology (PHP), a client side language (JavaScript), and a database system (MySQL) for storing and manipulating the records for the whole system. We have collection of tables in the database for keeping related records separately. The tables include:

- users - for keeping information about all the users,

- course - for records about courses,

- schedule - for lecture schedule details,

- attendance - for attendance related information.

To gain access into the application the users must login with their credentials, i.e. username and password as illustrated in Fig. 5.

Information about the lecturers, students as well as the courses is stored in the database. We have three different users of the application; administrator, lecturers, and students. The administrator is responsible for managing the remaining two users.

At the beginning, the administrator will create the users with basic information that they can update later, set the semester, and create courses for the program. The lecturers will assign to themselves the courses they are taking in a semester, and create a course schedule. Course schedule information must include date, beginning and end of class time, etc. The students must register for courses before they are allowed to attend a class. Each time a student register for a course an entry will be automatically created in the attendance table with absent as a default status value. This default value can only be changed when the student register for attendance for that class.

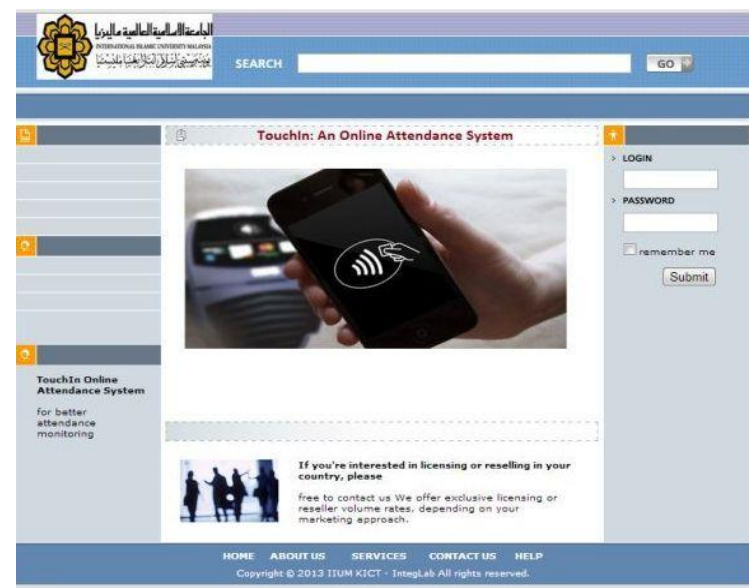

Fig. 5. Web based attendance system login page.

\section{TOUCHIN IN ACTION}

In order to make sure that the system is functioning as expected, we tested it using some sample data. In this section we will explain only the process from when the lecturer's device receives student information, since the process before this is explained in Section III.

When the lecturer's NFC-enabled device send the information (Student ID, device ID, and Course code) to the server, the data is processed and the server performs several operations to do appropiate processings. The processing include: checking the database for existence of the student ID, matching the student ID with the registered device ID, making sure the student register for that course, confirming the course schedule, etc.

For doing the checking and matching operations, data on current date and time are obtained from the server in order to compare with the date and time in the schedule. In any of the above case, if the condition fails an error message will be sent to either student or lecturer depending on the situation. Conversely, if all the conditions are satisfied, a succesful message will also be conveyed and then the student status will change from 'absent' to 'present' and amount of time (in minutes) the student is late will also be recorded in the database. The flow of the whole process is represented in Fig. 6.

\section{CONCLUSIONS AND FUTURE WORK}

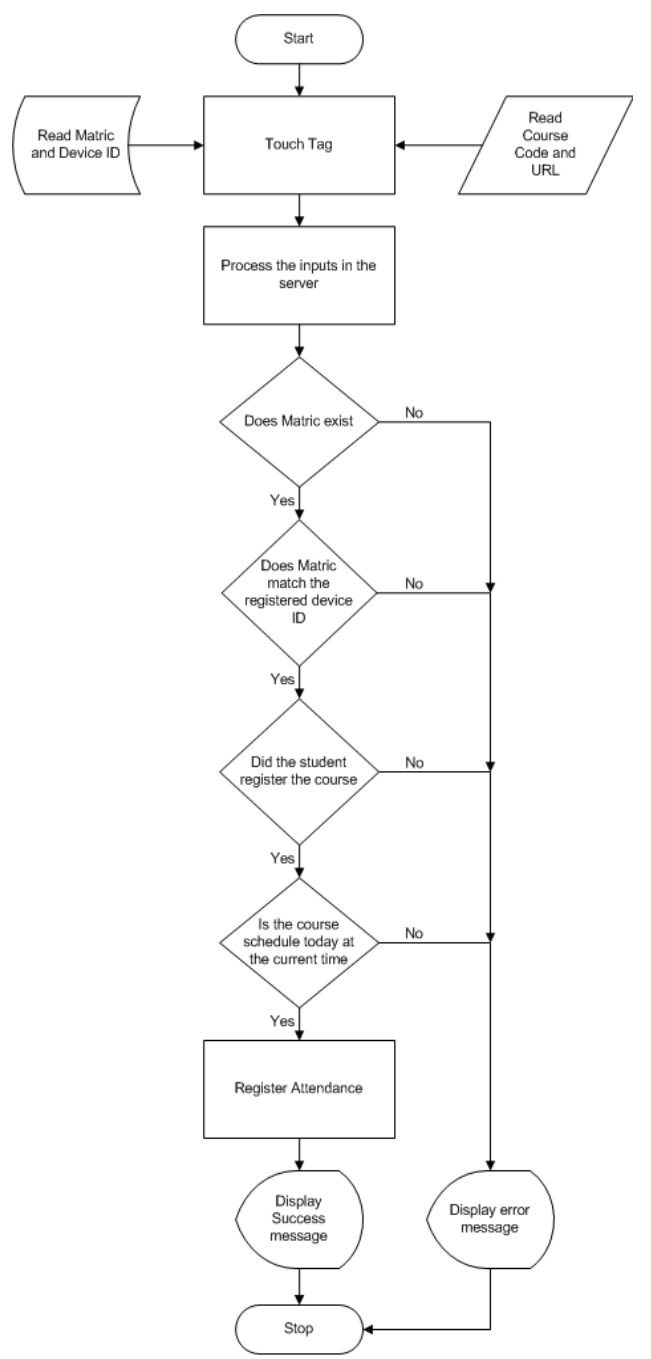

Fig. 6. Attendance registration process.

Attendance management in education institutions is a very important issue, because in most institutions attendance is part of student's continuous assessment or is a condition that student must met before they are allowed to sit for examinations. The system presented in this paper will 
substantially improve the current day's attendance registration system and eliminate many paper works involved in it. Other benefits include eliminating the chance of losing attendance data, different attendance reports can be easily generated by a click of mouse, simplifying the decision making process related to attendance, etc. One of the major distinct characteristics of our proposed system is that the hardware required are minimal, i.e. only NFC tag and NFC-enabled mobile device. This is as oppose to most systems where other devices like NFC or RFID reader is required. As well, the system can cater for several types of situations, whether the student has an NFC-enabled device or not.

In the future, the system will be implemented in a real institution setup in order to validate it. The system can also be improved by updating the client application in receiving response and be able to reply back directly from the application.

\section{ACKNOWLEDGMENT}

The authors would like to express sincere gratitude and appreciation to Integ Lab of Kulliyyah (Faculty) of Information and Communication Technology, International Islamic University Malaysia for supporting us with facilities that can make this system to be developed and studied further.

\section{REFERENCES}

[1] V. Coskun, K. Ok, and B. Ozdenizci, Near Field Communication: From Theory to Practice, 1st ed., West Sussex, United Kingdom: John Wiley \& Sons, 2011.

[2] M. A. Ayu, T. Mantoro, S. A. Ismail, and N. S.Zulkifli, "Rich Information Service Delivery to Mobile Users Using Smart Posters," presented at the 2nd International Conference on Digital Information and Communication Technology (DICTAP) 2012, Bangkok, Thailand, 16-18 May 2012, ISBN: 978-1-4673-0734-5.

[3] S. K. Jain, U. Joshi, and B. K. Sharma, "Attendance Management System," Masters Project Report, Rajasthan Technical University, Kota.

[4] M. Mattam, S. R. M. Karumuri, and S. R. Meda, "Architecture for Automated Student Attendance," in Proc. IEEE Fourth International Conference on Technology for Education (T4E 2012), pp.164-167, 18-20 July 2012, doi: 10.1109/T4E.2012.39.

[5] Z.-G. Zhang, P. Gong, L.-J. Cao, and Y.-L. Chen, "Information Technologies and Applications in Education," First IEEE International Symposium on Digital Object Identifier, 2007, pp. 606-609.

[6] M. K. P. Basheer and C. V. Raghu, "Fingerprint attendance system for classroom needs," in Proc. India Conference (INDICON), 2012 Annual IEEE, pp. 433-438, 7-9 Dec. 2012.

[7] BISAM-BIS attendance Management System by BIS Software Development Services PVT Limited. [Online]. Available: http://www.softwarehouse.co/school-attendance-brochure.pdf

[8] S.-H. Geng, G.-M. Li, and W. Liu, "Design and Implement of Attendance Management System Based on Contactless Smart IC Card," in Proc. International Conference on Computer Science and Electronics Engineering (ICCSEE), vol. 3, pp. 290-294, 23-25 March 2012, doi: 10.1109/ICCSEE.2012.196.

[9] T. S. Lim, S. C. Sim, and M. M. Mansor, "RFID based attendance system," IEEE Symposium on Industrial Electronics \& Applications 2009 (ISIEA 2009), vol.2, pp. 778-782, 4-6 Oct. 2009, doi: 10.1109/ISIEA.2009.5356360.

[10] M. Kassim, H. Mazlan, N. Zaini, and M. K. Salleh, "Web-based student attendance system using RFID technology," in Proc. IEEE Control and System Graduate Research Colloquium (ICSGRC 2012), pp. 213-218, 16-17 July 2012, doi: 10.1109/ICSGRC.2012.6287164.
[11] M. Strommer et al., Smart NFC Interface Platform and its Applications, in T. Tuikka and M. Isomursu, (Eds.), Touch the Future with a Smart Touch, 2009.

[12] R.-K. Outi. (2009). NFC for children. Touch the Future with a Smart Touch. [Online]. Available: http://www.vtt.fi/inf/pdf/tiedotteet/2009/T2492.pdf

[13] M. Ervasti, M. Isomursu, and M. Kinnula, "Experiences from NFC Supported School Attendance Supervision for Children," in Proc. Third International Conference on Mobile Ubiquitous Computing, Systems, Services and Technologies, 11-16 Oct. 2009, doi 10.1109/UBICOMM.2009.9, pp. 22-30.

[14] A. De-Gea-Garcia et al., "The Smart University Experience: An NFC-Based Ubiquitous Environment," in Proc. Sixth International Conference on Innovative Mobile and Internet Services in Ubiquitous Computing (IMIS 2012), 4-6 July 2012, doi: 10.1109/IMIS.2012.110, pp. 799-804.

[15] B. Benyo, B. Sodor, T. Doktor, and G. Fordos, "University life in contactless way - NFC use cases in academic environment," in Proc. IEEE 16th International Conference on Intelligent Engineering Systems (INES 2012), 13-15 June 2012, doi 10.1109/INES.2012.6249887, pp. 511-514.

[16] B. Benyo, B. Sodor, T. Doktor, and G. Fordos, "Student attendance monitoring at the university using NFC," in Proc. Wireless Telecommunications Symposium (WTS), 2012, 18-20 April 2012, doi: 10.1109/WTS.2012.6266137, pp. 1-5.

[17] S. B. Patela and N. K. Jainb, "Near Field Communication (NFC) based Mobile Phone Attendance System for Employees," International Journal of Engineering Research \& Technology, vol. 2, issue 3, March 2013.

[18] H. Ninomiya et al., "Bridging SNS ID and user using NFC and SNS: Design of NFC and SNS based event attendance management system," in Proc. International Conference on Anti-Counterfeiting, Security and Identification (ASID 2012), 24-26 Aug. 2012, doi: 10.1109/ICASID.2012.6325346, pp. 1-5.

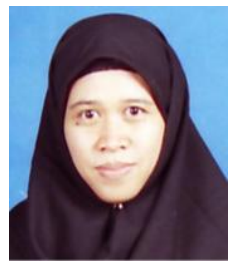

Media Anugerah Ayu graduated with a BSc from Department of Agroindustial Technology, Bogor Agricultural University (IPB), Bogor, Indonesia and received her MSc from School of Advanced Technology, Asian Institute of Technology (AIT), Bangkok, Thailand. She obtained her $\mathrm{PhD}$ in Information Science and Engineering in 2007 from Department of Engineering, College of Engineering and Computer Science (CECS), the Australian National University (ANU), Canberra, Australia.

She was an associate professor at Department of Information Systems, Faculty (Kulliyyah) of Information and Communication Technology (KICT), International Islamic University Malaysia, in Kuala Lumpur. Currently, she holds a position as Head of Institute of Social Development and Community Outreach in Universitas Siswa Bangsa Internasional (USBI), Jakarta, Indonesia. She has published more than 70 research papers in international journals, conferences, book chapters and books in IT related areas. She also has three patent pendings to her credits in IT related research and innovation. Her research interest is set around the area of web application development, ubiquitous computing, mobile application for intelligent environment, activity recognition, ICT for teaching and learning, and decision support systems.

Dr. Ayu is a member of IEEE and a senior member of IACSIT. She served as a Program Chair of The Third ICT4M Conference in 2010 which is indexed by SCOPUS. She also has served as a program committee member and a reviewer in some international conferences. She has received several awards from international and national innovation exhibition events for her research and innovation products.

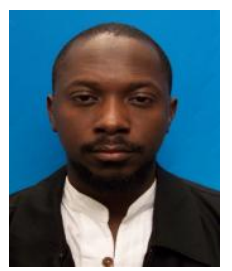

Barroon I. Ahmad received his degree and master of computer science from Usmanu Danfodiyo University Sokoto in 2006, and Ahmadu Bello University Zaria in 2009 respectively both in Nigeria.

$\mathrm{He}$ works as a lecturer with Ahmadu Bello University Zaria, Nigeria. He is currently pursuing his $\mathrm{PhD}$ in International Islamic University Malaysia. His research interests are Health Information Technology, Mobile and Pervasive Computing, Internet and Web Application Development.

Mr. Ahmad is a member of NCS and IEEE. 